\title{
Notifications of industrial chemical cyanosis poisoning in the United Kingdom 1961-80
}

\author{
DK SEKIMPI ${ }^{1}$ AND RD JONES ${ }^{2}$ \\ From PO Box 16422, ${ }^{1}$ Kampala, Uganda, and Epidemiology and Medical Statistics Unit, ${ }^{2}$ Health and Safety \\ Executive, Bootle, Merseyside, UK
}

\begin{abstract}
In 325 cases of industrial chemical cyanosis notified to Her Majesty's Factory Inspectorate for 1961-80 the incidence of poisonings showed considerable seasonal variation with substantially greater numbers occurring in the summer months. A correlation between the number of poisonings in any one year and the hotness of that summer was also shown. The vast majority of incidents occurred during the manufacture of chemicals or dyestuffs, and two particular workplaces were responsible for $70 \%$ of the cases. Poisoning by amino compounds appear to produce early cyanosis whereas poisoning by nitro compounds tended to produce delayed cyanosis. These latter compounds were also more likely to produce anaemia. Methaemoglobin was determined in $45 \%$ of cases with results ranging from less than a few per cent to over $50 \%$. Despite concentrations of MetHb over $50 \%$, several workers complained only of headache and their blue appearance.
\end{abstract}

Aniline and related compounds have been in industrial use since the nineteenth century and their importance, particularly in the dyestuff industry, is still considerable. Acute aniline poisoning has been recognised since the early days of its use in industry and its acute toxicity is still a problem. Aniline poisoning shows itself as clinical cyanosis which may also be referred to as anilism or "blueing up." This chemical cyanosis is brought about by conversion of normal haemoglobin to methaemoglobin and has been a notifiable industrial disease in the United Kingdom since 1924. ${ }^{1}$ The terms "anilism" and "aniline poisoning" are often applied to chemical cyanosis even when the chemical responsible is not aniline. Chemical cyanosis may be produced by several compounds including nitrates, nitrites, and phenacetin analgesics as well as by the amino and nitro compounds of chlorobenzene, benzene, and its homologues. ${ }^{2}$ The term anilism is usually restricted to poisoning by these benzene derivatives. In this paper the terms anilism or aniline poisoning will refer to chemical cyanosis due to amino and nitro derivatives of chlorobenzene, benzene, and its homologues. Exposure to these compounds may occur during production or during their use in the manufacture of dyestuffs, plastics, pesticides, pharmaceuticals, and many other substances.

Accepted 1 July 1985

\section{Routes of absorption}

These compounds may be absorbed by ingestion, inhalation, or through the skin. In an industrial context it is the two latter routes of absorption that are important. Volatile liquids such as aniline and nitrobenzene may be inhaled as vapour, whereas solids such as p-nitrotoluene and dinitrobenzene may be inhaled in the form of fine dusts or as an aerosol of their solutions. All these compounds may be absorbed through the skin.

\section{Clinical effects}

Conversion of haemoglobin to methaemoglobin reduces the amount of haemoglobin available for oxyhaemoglobin formation. The oxygen carrying capacity of the blood is thus reduced, which decreases the amount of oxygen available to the tissues.

Methaemoglobin (MetHb) gives blood a darker colour, often described as chocolate brown, which results in the clinical picture of cyanosis once concentrations of methaemoglobin reach $15 \% .^{3}$ Symptoms may not occur until the methaemoglobin concentration has reached over $40 \%$, when light headedness, ataxia, and weakness may be noticed. At higher concentrations of MetHb, tachycardia and dyspnoea develop. Alcohol consumption is said to be conducive to 
the development of MetHb. ${ }^{4}$ In severe cases coma, cardiac failure, and eventual death may result. ${ }^{4}$ Exposure to these compounds can result in the production of an anaemia, which may be haemolytic in type. $^{56}$

Apart from causing anaemia, chronic exposure may result in the production of subcyanotic levels of $\mathrm{MetHb}$, thereby making the individual more susceptible to any subsequent major exposure to a cyanogenic compound.

The degree and type of toxic effect observed will vary according to which particular agent exposure has occurred. To some extent these differences will be due to the physical state of the compound concerned but also relates to the actual biochemical properties of these agents. $^{7}$

\section{Methods}

Under section 82 of the Factories Act 1961, it is the duty of an occupier or medical practitioner to notify the Chief Inspector of Factories of any poisoning due to amino or nitro derivatives of benzene, chlorobenzene, or their homologues that have occurred on premises subject to that Act. ${ }^{1}$ For each case notified to him during 1961-80 the Chief Inspector requested a report from the appropriate doctor (medical inspector of factories or appointed factory doctor before 1973: employment medical adviser since then). Copies of these reports were sent to the head office of

Table 1 Chemical cyanosis syndrome: agents commonly responsible

\begin{tabular}{ll}
\hline Chloroaniline & CA \\
Dinitrobenzene & DNB \\
Nitroaniline & NA \\
Paratoluidine & PT \\
Nitrobenzene & NB \\
Nitrochlorobenzene & NCB \\
Aniline & AN \\
Orthotoluidine & OT \\
Nitrotoluidine & NT \\
Dichloroaniline & DCA \\
\hline
\end{tabular}

the medical division of Her Majesty's Factory Inspectorate, which in 1972 became the Employment Medical Advisory Service. The notifications relating to events occurring from 1 January 1961 to 31 December 1980 provide the basic data for the study described here.

D A T A S O U R C E

All records of aniline poisoning in Britain notified from 1 January 1961 to 31 December 1980, which were accepted as such by the Medical Adviser concerned, were scrutinised. Certain basic facts for each notification had been recorded on a standard HMFI form, the format of which changed twice between 1961 and 1980. Further details about each particular case were added to a variable degree by the reporting factory inspector and verifying physician. Thus the amount of detail available on each particular case varied considerably.

\section{EXTR A C T I O N O F D A T A}

An a priori list of criteria of interest was drawn up. This list was applied to each individual record and the appropriate information extracted. This covered both the information obtainable from the structed data on the record form (age and sex) and that which had to be gleaned from the free text. Table 1 lists the chemicals reported in these cases. When exposure to more than one chemical had occurred, the investigating physician related the incident to the agent he considered to be responsible. When two chemicals were considered to have played an important part in the poisoning both were recorded. When two routes of absorption were probably relevant, both were noted. The latent period of poisoning was inferred from the last period of exposure to the appearance of signs and symptoms of anilism.

Owing to the open nature of the information and the fact that it was collected and recorded by different physicians over a long period, the results are mainly descriptive frequency distributions. Since the baseline

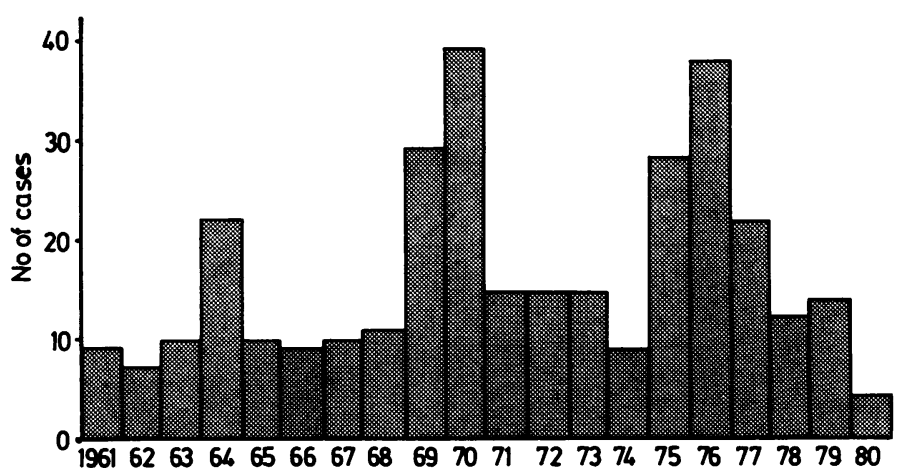

Fig 1 Aniline poisoning notifications. 


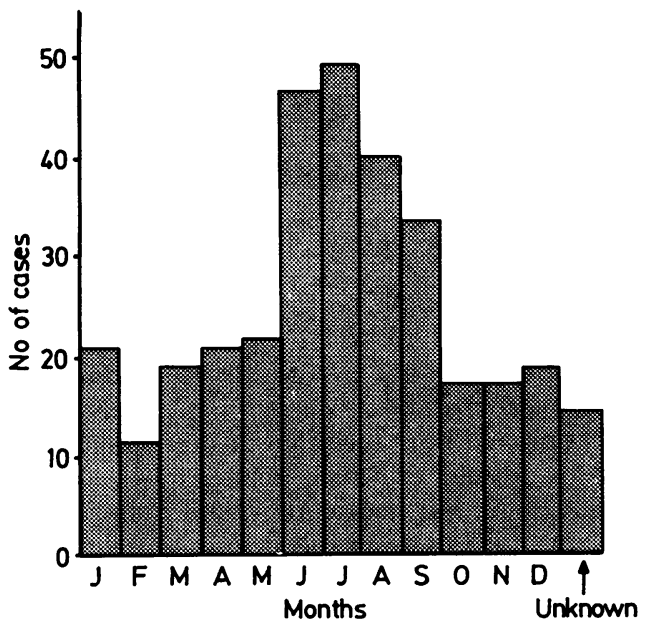

Fig 2 Aniline poisoning notifications by month of occurrence.

population of workers exposed was not known (this being variable over time and from place to place), no calculation of incidence was possible.

\section{Results}

In the period studied 325 notifications of poisoning

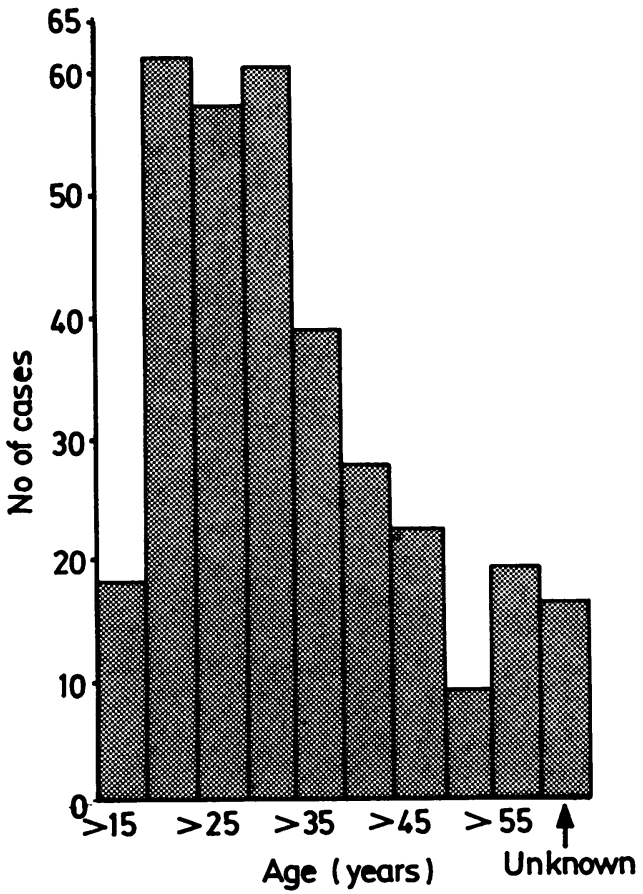

Fig 3 Age distribution of notified people. were reported from 317 incidents. In each of eight incidents two people were affected. For 44 of the 325 notifications at least one previous incident affecting that person had been recorded. The 325 notifications relate to 299 separate individuals.

TIME TREND

Figure 1 shows the annual frequency distribution over the 20 years studied. Peak occurrences are seen in 1970 and 1976. Figure 2 shows the distribution of cases by month. The number of cases reported increases during the summer months, June to September.

SEX

Only two of the 325 notifications were for women workers. One worked in a laboratory and drank from a contaminated vessel, providing the only case of poisoning due to ingestion in this study. The other woman affected was a process worker in a chemical plant.

AGE

Age was recorded in 311 cases and ranged from 17 to 63 with a mean of 33.2 years. Figure 3 shows the age distribution of the notified cases.

INDUSTRY TYPE

Notifications were received from 43 different workplaces; $94.5 \%$ of cases occurred during chemical or dyestuff manufacture. Eight cases occurred during the manufacture of pharmaceuticals, three during rubber manufacture, and an occasional case each for road haulage, paper making, and laboratory work. One chemical manufacturing plant was responsible for 118 $(36 \%)$ notifications and one dyestuff producing plant for $111(34 \%)$ notifications.

\section{ACTIVITY TYPE}

The work activity at the time of poisoning was interpreted from records and divided into four types-that is, process operation, maintenance work, laboratory work, and a miscellaneous activity group. Seventy

Table 2 Relation between experience at process and poisoning

\begin{tabular}{|c|c|c|c|}
\hline $\begin{array}{l}\text { Period of employment at } \\
\text { process }\end{array}$ & $\begin{array}{l}\text { No of } \\
\text { notifications }\end{array}$ & $\%$ & \\
\hline $\begin{array}{l}<48 \text { hours } \\
2 \text { days-1 month } \\
2-11 \text { months }\end{array}$ & $\begin{array}{l}29 \\
30 \\
73\end{array}$ & $\left.\begin{array}{l}12 \cdot 0 \\
12 \cdot 5 \\
30 \cdot 3\end{array}\right\}$ & $54 \cdot 8$ \\
\hline $\begin{array}{l}12-35 \text { months } \\
3-5 \text { years } \\
\geqslant 6 \text { years }\end{array}$ & $\begin{array}{l}58 \\
25 \\
26\end{array}$ & $\left.\begin{array}{l}24 \cdot 1 \\
10 \cdot 4 \\
10.8\end{array}\right\}$ & $45 \cdot 2$ \\
\hline Total & 241 & $100 \cdot 0$ & \\
\hline
\end{tabular}




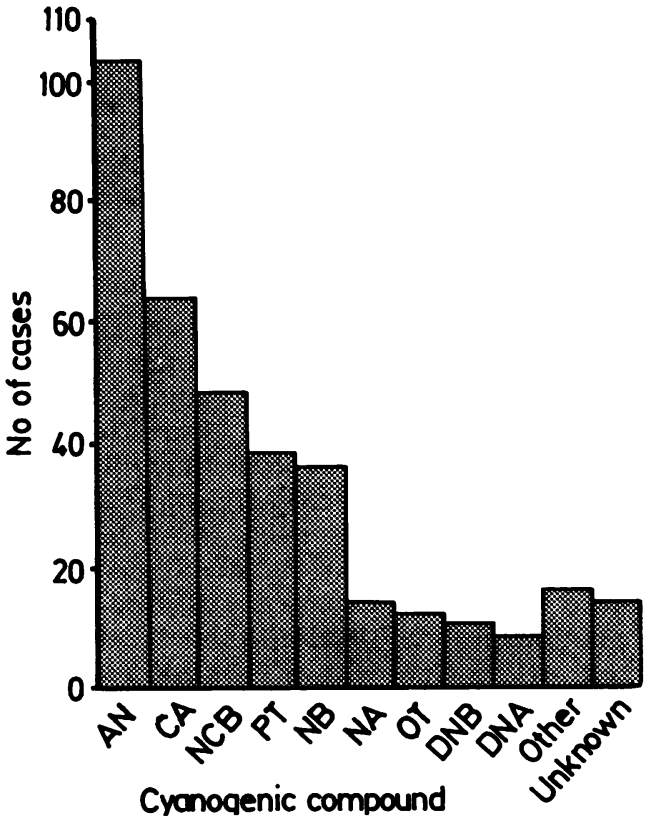

Fig 4 Compounds responsible for aniline poisoning. (Although aniline poisoning had been notifiable since 1924, poisoning by other nitro, amino, or amino derivatives of benzene homologues were not included in the wording of the statute until 1966(1). It had been the practice, however, for at least some such poisonings to be notified under aniline poisoning. From 1961 to 1965 compounds other than aniline were reported slightly more often than those due to aniline itself. Proportion of cases of poisoning by other compounds in relation to cases produced by aniline increased after 1966 and by the mid-1970s were well in excess of those due to aniline so that poisoning by compounds other than aniline have probably been underreported in first five years of study period.)

three per cent of cases occurred during process work and $18 \%$ during plant maintenance.

\section{JOB EXPERIENCE}

In 241 notifications details of the duration of employment of the worker was recorded. This information is shown in table 2 and shows that $54.8 \%$ of cases occurred in workers in their first year of employment.

\section{CHEMICAL AGENTS}

Figure 4 shows the distribution of cases according to the compound deemed responsible for the poisoning. In 13 of the original 325 notifications the compound
Table 4 Symptoms recorded

\begin{tabular}{lll}
\hline Symptom(s) & No of cases & $\begin{array}{l}\text { Percentage (of all } \\
\text { cases) }\end{array}$ \\
\hline Headache & 98 & $30 \cdot 2$ \\
Weakness & 85 & $26 \cdot 2$ \\
Dizziness/vertigo & 51 & $15 \cdot 7$ \\
Nausea/vomiting & 50 & $15 \cdot 4$ \\
Chest symptoms & 45 & $13 \cdot 8$ \\
Collapse/loss of consciousness & 26 & 8.0
\end{tabular}

responsible was not recorded. The total number of ascriptions of compounds to cases is 348 because some cases were deemed to have involved appreciable exposure to more than one compound. Aniline was considered to be responsible in about $30 \%$ of the 312 cases where the agent(s) was noted and for which information on responsible agent(s) was available. Other compounds producing more than 10 cases a year were chloroaniline, paratoluidine, nitrobenzene, and nitrochlorobenzene.

\section{ROUTE OF ABSORPTION}

Information on the route of absorption was missing in 44 cases. Poisoning by ingestion occurred in one case previously described. Of the remaining 280 cases, 141 resulted from skin absorption, 90 were due to inhalation, and 49 were considered to result from absorption through both the skin and the lungs.

Of the 325 notifications, $169(52 \%)$ occurred during the hot months June to September. Table 3 shows the proportion of cases incurred by the different routes of absorption in the summer months and those incurred in the remaining months. The seasonal variation observed does not appear to affect the relative proportion of cases due to the various routes of absorption.

\section{SYMPTOMS AND SIGNS}

The classic sign of anilism is greyish blue cyanosis due to methaemoglobinaemia and this was recorded in all but four of the 325 notifications. The four cases where clinical cyanosis was not observed were reported because of symptoms attributable to poisoning or on laboratory evidence of methaemoglobinaemia after a history of acute exposure to a cyanogenic agent. The commonest presenting complaint in these workers was their blue appearance. Other symptoms recorded are shown in table 4 with the frequency with which they were noted. Of the 26 individuals who collapsed or lost consciousness, seven were recorded as having

Table 3 Route of absorption: summer months (June-September)

\begin{tabular}{lllll}
\hline Route of absorption & Skin & Inhalation & Skin/lungs & Total \\
\hline No of notifications & $(77)$ & $(46)$ & $(26)$ & $(169)$ \\
Percentage & $45 \cdot 6$ & $27 \cdot 2$ & $15 \cdot 3$ & $100 \cdot 0$ \\
\hline
\end{tabular}


drunk alcohol just before collapsing. In the seven cases with a positive history of alcohol induction, the cyanogenic agent responsible was a nitrocompound (nitrobenzene 3 cases, nitrochlorobenzene 2, and dinitrobenzene 2). Other clinical features are shown in table 5 .

\section{ONSET OF SYMPTOMS}

In $278(85 \%)$ cases symptoms were noted while the affected person was at work. Of these, 229 cases were identified on the day of exposure and 14 were noted a day or more after the exposure incident deemed responsible had occurred. In 35 cases there was an insidious onset of symptoms without any history of a definite precipitating exposure. Of these, eight were identified on medical examination. In $32(9.9 \%)$ cases symptoms were noted when the affected person was away from work (either at home or out drinking). For the remaining $15(4.6 \%)$ cases there was no record indicating the latent period between exposure and onset of symptoms. For the purpose of interpretation, the 229 cases whose symptoms developed while at work on the same day of exposure are described as "early cases." The 81 cases whose symptoms developed insidiously or some definite time after the "working" day on which the poisoning occurred, are described as "delayed" cases. Because two compounds could be responsible in one case, the total for early cases is more than 229 . As it happens only one compound was implicated for each of the 81 delayed cases.

Table 6 Latent period in relation to cyanogenic compounds

\begin{tabular}{lrlrrr}
\hline Compound & \multicolumn{2}{c}{ Early cases } & \multicolumn{2}{c}{ Delayed cases } & Total \\
\hline AN & 84 & $(85 \%)$ & 15 & $(15 \%)$ & 99 \\
CA & 45 & $(87 \%)$ & 7 & $(13 \%)$ & 52 \\
NCB & 23 & $(46 \%)$ & 27 & $(54 \%)$ & 50 \\
PT & 34 & $(94 \%)$ & 2 & $(6 \%)$ & 36 \\
NB & 15 & $(56 \%)$ & 12 & $(44 \%)$ & 27 \\
NA & 7 & $(64 \%)$ & 4 & $(36 \%)$ & 11 \\
OT & 5 & $(83 \%)$ & 1 & $(17 \%)$ & 6 \\
DNB & 3 & $(50 \%)$ & 3 & $(50 \%)$ & 6 \\
DCA & 3 & $(60 \%)$ & 2 & $(49 \%)$ & 5 \\
Other & 10 & $(83 \%)$ & 2 & $(17 \%)$ & 12 \\
Unknown & 7 & $(54 \%)$ & 6 & $(46 \%)$ & 13 \\
Total no of cases & 229 & $(74 \%)$ & 81 & $(26 \%)$ & 310 \\
\hline
\end{tabular}

Table 6 shows a breakdown of incidents by time of onset of symptoms and responsible agent. From this rather crude presentation of the data, aniline, paratoluidine, and chloroaniline appear more likely to cause early symptoms whereas nitrochlorobenzene and nitrobenzene produced roughly as many delayed cases as they did early ones.

\section{MetHb AND DEGREE OF TOXICITY}

In only $45 \%$ (147) of cases was MetHb measured. The proportion of cases in which MetHb was determined gradually increased through the study period. From 1961 to 1965 in only five of 58 cases were any laboratory estimations carried out, whereas during 1976-80 91 cases occurred of which 63 were sampled for determination of MetHb. Thus many of the cases occurring in the early part of the study period, which included several workers severely affected clinically, were not sampled for MetHb. Of those that were, the highest MetHb reported was $65 \%$ and another five returned results of $50 \%$ or more. Despite these high MetHb results, these workers complained of no more than headache and dizziness. Among the 12 workers who returned a MetHb between $30 \%$ and $50 \%$, seven complained only of cyanosis with no other signs of symptoms. Of the remaining five, one individual collapsed and the other four complained of headache.

\section{METHAEMOGLOBIN CONCENTRATIONS}

Methaemoglobin results were available for 147 of the

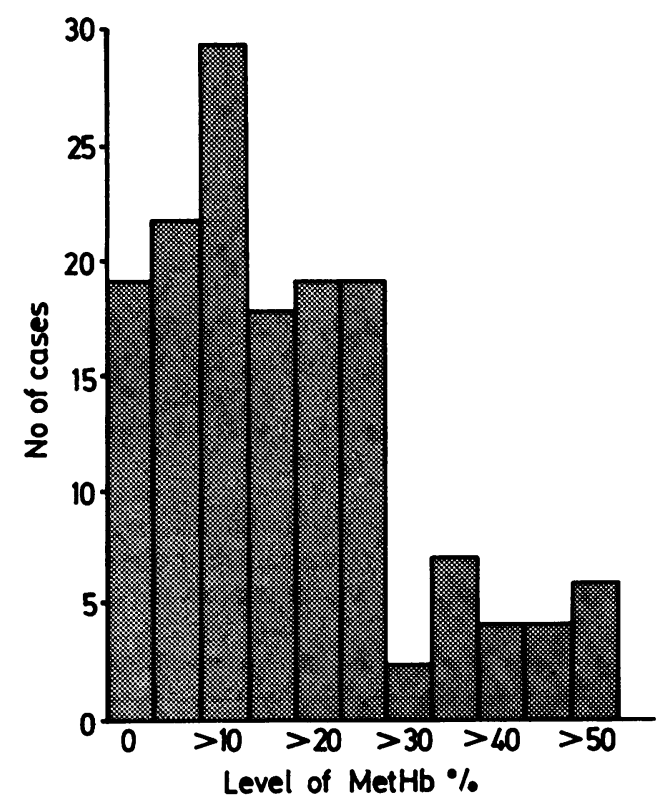

Fig 5 Concentrations of methaemoglobin. 


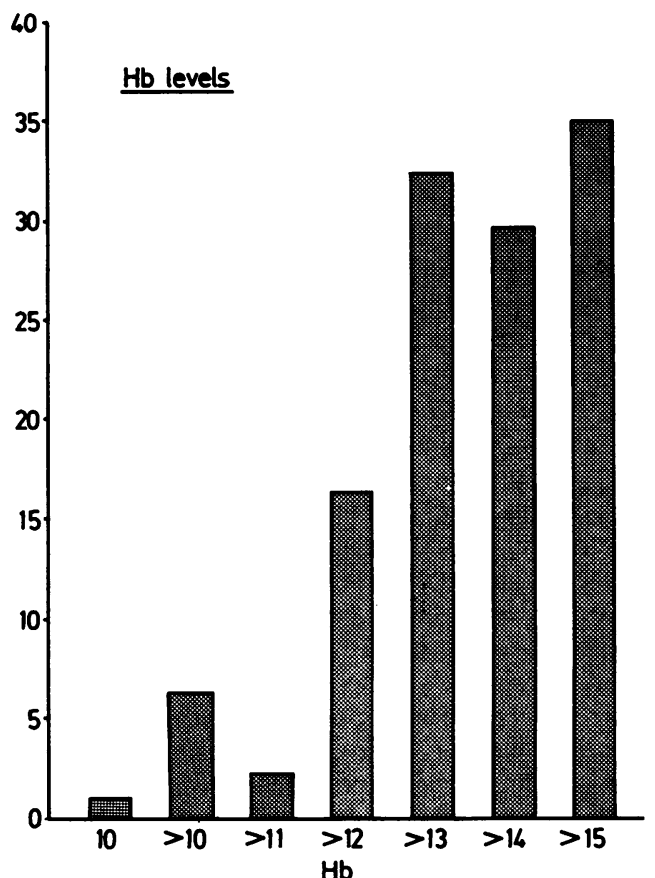

Fig 6 Hb levels for the 125 cases where this was recorded.

cases and fig 5 shows the distribution of cases by concentration of methaemoglobin. Haemoglobin was estimated in 125 cases and a blood film carried out on 25 individuals. Figure 6 shows the results for haemoglobin. For the 25 cases where blood films were studied, 14 showed features of haemolysis, the compound responsible in each of these cases being nitrobenzene 5, nitrochlorobenzene 8 , aniline 2 , paratoluidine 2 , chloroaniline 1 , and substance not specified 2. Of the 60 cases where haemoglobin was noted to be less than $14 \mathrm{~g} / 100 \mathrm{ml}$, the nitrocompounds (NB, NCB, and DNB) were recorded as the responsible agent in $29(48.3 \%)$ cases. The contribution of these agents to all cases, however, was only $27.5 \%$. The amino compounds, aniline, chloroaniline, and nitroaniline, on the other hand, were responsible for only 13 of the 60 cases where

Table 7 Type of treatment (325 notifications)

\begin{tabular}{lll}
\hline Type of treatment & No of cases & Percentage \\
\hline Methylene blue (oral or intravenous) & 142 & 43.7 \\
Oxygen & 129 & 39.7 \\
Rest & 110 & 33.8 \\
Shower and change of clothing & 109 & 33.5 \\
Vitamin C & 23 & $7 \cdot 1$ \\
Redoxon & 15 & 4.6 \\
Vitamin B & 14 & 4.3 \\
No treatment recorded & 54 & 16.6 \\
\hline
\end{tabular}

haemoglobin was less than $14 \mathrm{~g}(21.7 \%)$, whereas they contributed some $55 \%$ to the series overall.

One man who developed jaundice did so after two consecutive exposure incidents within 10 days. The first incident was due to chloroaniline but the compound was not recorded in the second episode. There was good evidence of a reticulocytosis and the jaundice was assumed to be haemolytic in nature.

\section{TREA TMENT}

Table 7 lists the various treatments recorded in the 325 notifications. In two cases it was stated that injection of methylene blue had to be stopped because of unbearable pain. In one of these cases a painful swelling developed at the injection site.

\section{Discussion}

The data used in this study were collected over 20 years by many different individuals. Though standard forms were completed on those affected, much of the information on any given incident was provided in a non-structured textual form. These records have severe limitations as the basis of any study but are of interest because they provide considerable information on such a large number of cases of anilism. Limitations of the records, however, must be recognised from the outset, and those limitations include the incompleteness of recording and bias introduced by various reporters. Reliability is further compromised by the fact that the individual report may have been made some time after the incident occurred so that there is considerable reliance on memory. It is not possible, either, to estimate the degree of underreporting that occurs in notification systems such as this. Bias will be introduced by the variable motivation and interest of the reporting physician or factory inspector, so that some minor cases are reported in great detail whereas reports of some major poisonings may be rather sketchy.

When a compound is generally thought to have an effect on a particular biochemical parameter or physiological function, that effect is more likely to be looked for than where it might not have been expected. Data on toxic effects will therefore be biased towards reinforcing already held views of toxicity.

The fat solubility of these agents and their modest water solubility makes the skin an important route of absorption in industrial poisoning. ${ }^{37}$ Indeed, it has been said that for some compounds the principal risk of absorption is skin contact. ${ }^{8}$ In this series over $50 \%$ of cases would seem to have occurred by virtue of skin absorption alone and absorption via this route was considered significant in $68 \%$ of poisonings. This underlines the importance of skin absorption and the consequent need for thorough skin washing and 


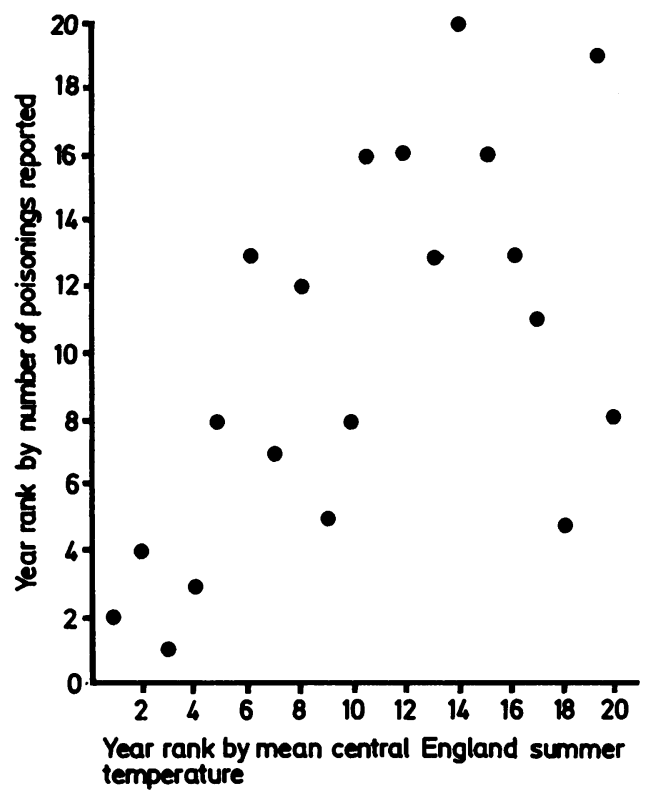

Fig 7 Scattergram of years ranked by hotness of summers and numbers of poisoning notifications.

change of clothing as an essential part of treatment.

While there is no secular trend, the years ranked as the first four in terms of the number of cases occurring were also the four hottest summers in the 20 years studied. The ranked incidence of poisoning was plotted against the ranked mean summer temperature for central England for each year (fig 7) and the rank coefficient was calculated to be $0 \cdot 6$. Thus annual incidence appears to be substantially influenced by the weather.

Ignoring the extremely high peaks during hot summers there does not appear to be any sustained decreased incidence of anilism. Whereas the last annual figure given here for 1980 appears low, seven cases were reported in 1981 and six in 1982 which is of the same order of magnitude as that found at the beginning of our study period.

The seasonal variation shows an obvious increase in incidents during the summer months, with over $50 \%$ of the cases occurring between 1 June and 30 September. As incidents due both to skin absorption and to inhalation are found in the same proportions during the summer months and the rest of the year, it seems that the factors leading to increased skin absorption (such as increased peripheral vasodilation and perspiration and the wearing of fewer clothes) are at least as important in producing this number of poisonings in hot weather as increased volatility, leading to increased absorption through the lungs. The increase may be due to the less stringent use of protec- tive gear during hot weather when its wearing may be uncomfortable. It is interesting to note that of the eight cases where protective clothing was available but not used, six occurred in June or July and two in May. This seasonal variation in poisonings has been known for many years in the industry and was demonstrated by Linch. ${ }^{7}$

The sex distribution of these incidents undoubtedly reflects the preponderance of male labour in these industries. The age structure of the people poisoned may be representative of the age structure of workers in the industry concerned. This is no suggestion here of younger people being particularly susceptible, although there is no means of knowing what the incidence of poisoning is in any age group without having denominator population data. Finding that $55 \%$ of cases whose experience was recorded had worked less than one year at the process may suggest inexperience as a predisposing factor, but if labour turnover was high it may merely reflect a preponderance of short term workers in the population. If the proportion of short term workers found among the poisoning cases merely reflects the experience profile of the total labour force, however, this would mean that one in every four working on site at any one time would have worked there for less than one month. This seems an unlikely proportion, and it is more plausible that inexperience is an important factor in causation of these accidents. As is so often found with occupational hazards, non-process workers, especially maintenance men, contribute significantly to the overall incidence. Eighteen per cent of all notifications came from these workers. The fact that two workplaces contributed $70 \%$ of all notifications shows the ease with which local circumstances at either of those workplaces might substantially affect returns for aniline poisonings and indeed many other features reported in this study.

The amino compounds, aniline, chloroaniline, and paratoluidine, which were noted to cause early cyanosis, account for $63 \%$ of all notifications whereas the nitro compounds noted to be more likely to cause delayed cyanosis and anaemia accounted for only $27 \%$ of notifications. These findings may suggest that a great deal of emphasis is put on cyanosis for diagnosis so that for some cases in whom cyanosis did not appear, notifications are not received. On the other hand, the amino compounds may be more hazardous or more prevalent in the industry. Laboratory rather than clinical diagnosis might show a clearer picture of the effects of exposure, and it was encouraging to note that biological monitoring has become more popular in recent years. No deaths were reported in this series of chemical cyanotic poisonings.

Methylene blue was the most commonly recorded treatment but in two cases methylene blue injection 
was so painful that it had to be abandoned half way through and in one of these cases a swelling developed at the site of the injection.

With a large number of severe clinical cases missing $\mathrm{Hb}$ data it is not possible to confirm or refute the generally held views on the relation between MetHb and clinical effect. There were several high MetHb results returned for individuals who (apart from cyanosis) were only mildly affected. It is important to remember that the MetHB determinations were carried out over a substantial period by different methods, and the accuracy and reliability of these determinations will vary according to the methods of analysis that were in use at the time.

\section{References}

${ }^{1}$ Judge IF, Makin EA. Redgrave's health and safety in factories. London: Butterworth, 1976.
${ }^{2}$ Maclean D. Methaemoglobinaemia. In: Parmeggiani L, ed. ILO encyclopaedia of occupational health and safety. Geneva: International Labour Office, 1983:1355-6.

${ }^{3}$ Beard RR, Noe JT. Aromatic nitro and amino compounds. In: Clayton GD, Clayton FE, eds. Patty's industrial hygiene and toxicology. Vol. 2a. 3rd rev. New York: Wiley, 1981:2413-89.

${ }^{4}$ Scott TS, Munn A, Smagghe G. Aniline. In: Parmeggiani L, ed. ILO encyclopaedia of occupational health and safety. Geneva: International Labour Office, 1983:153-5.

${ }^{5}$ Okubo T, Shigeta S. Anaemia cases after acute m-dinitrobenzene (DNB) intoxication due to occupational exposure. Ind Health 1982;20:297-304.

${ }^{6} \mathrm{Linch} \mathrm{AL}$. Aromatic nitrocompounds. In: Parmeggiani L, ed. ILO encyclopaedia of occupational health and safety. Geneva: International Labour Office, 1983;1451-54.

${ }^{7}$ Linch AL. Biological monitoring for industrial cyanogenic aromatic nitro and amino compounds. Am Ind Hyg Assoc J 1974;35:426-32.

${ }^{8}$ Scott TS, Munn A, Smagghe G. Aromatic amines. In: Parmeggiani $\mathrm{L}$, ed. ILO encyclopaedia of occupational health and safety. $\mathrm{Ge}-$ neva: International Labour Office, 1983:141-7.

\section{Correction}

\section{Spirometric data and penetration of particles to the alveoli (March 1986).}

Table 2 should read " $1 \%$ confidence intervals." 